\title{
Continuous muscle fibre activity in an Indian male with additional evidence of terminal motor fibre abnormality
}

\author{
HYAM ISAACS \\ From the Department of Physiology, Witwatersrand University, Johannesburg, South Africa
}

Ever since the vindication of Galvani's demonstrations of biologically produced electricity and the subsequent development of the galvanometer, electricity has been used to study and test the functioning capacity of all excitable tissues. The study of nerve conduction, of motor-unit activity, and of the myoneural junction has advanced our. knowledge of neuromuscular disease as a whole.

Electromyography has proved to be of particular value in studying the group of diseases known as the myotonias, of which the two main classifications are myotonia congenita or Thomsen's disease and myotonia dystrophica.

Myotonia is exhibited usually by observing the muscles after a strenuous voluntary contraction or after percussion of those muscles most involved. Myotonia may also be produced by electrical stimulation of the nerve (usually after the second or third stimulus). In many suspected cases of myotonia dystrophica the myotonia may be minimal and escape clinical detection while the dystrophic features are all too obvious. It is in such cases that electromyography is most useful in confirming the myotonic nature of the disease. There are several variants of myotonia with special features, viz., paramyotonia and myotonia in the closely related adynamia episodica hereditaria. Myotonia is readily produced when concentric needle electrodes are used and moved in myotonic muscle, while percussion of the overlying muscle almost invariably produces myotonia. Myotonia produces a characteristic sound which has been compared to the starting of a motor cycle engine with revving and subsequent fading of engine noise as it is heard in the distance. The myotonic activity produced by muscle percussion is demonstrated oscilloscopically in Figure 1. Figure 2 demonstrates the response of normal muscle to percussion. It will be seen that normal muscle is virtually electrically silent until contraction is initiated. The defect in myotonia is clinically apparent only in the phase of relaxation following the initial contraction. The electrical activity during the period of delayed relaxation is referred to as the 'myotonic after-discharge'. Characteristically, the muscle 'warms up' with repetitive contractions so that the myotonic activity disappears for a time in that particular muscle.

There is a great deal of evidence to suggest that this defect in relaxation is consequent on abnormal muscle cell membrane function. This abnormality seems to cause pathological alterations of the intracellular-extracellular ratios of various ions, particularly potassium and chloride. That myotonia may accompany potassium ionic shift, as occurs in hyperpotassaemic paralysis, was demonstrated by Buchthal, Engbaek, and Gamstorp (1958). The

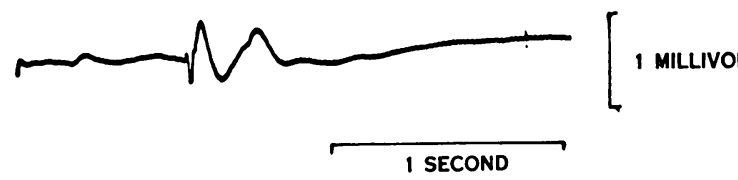

FIG. 2. Lack of electrical excitation following mechanical percussion in normal muscle.

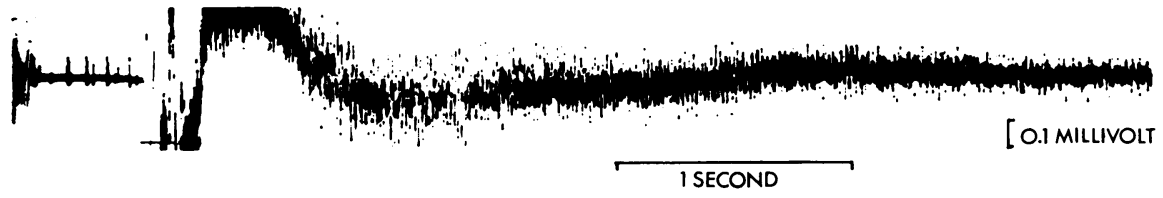

I SECOND
FIG. 1. Typical myotonic electrical activity following mechanical percussion of the muscle. 
relationship, however, is not a simple one. This is shown by the work of Creutzfeldt, Abbott, Fowler, and Pearson (1963) in their measurements of the muscle membrane potential in a patient with adynamia episodica. They found the resting membrane potential low during the normal period while during attacks of weakness it fell from -68.5 to -51.5 and $-46.3 \mathrm{mv}$. For $\mathrm{K}^{+}$shift alone to account for these electrical values, it would require levels of intracellular $\mathrm{K}^{+}$of 38 to $41 \mathrm{mEq}$./1. during an attack (Creutzfeldt et al., 1963). A further discrepancy in the relationship between myotonia and potassium is the fact that the muscles showing most irritability or myotonia are not the same as those showing most weakness during hyperkalaemic attacks. Weakness and hyperkalaemia, on the other hand, correlate well, as shown by Van der Meulen, Gilbert, and Kane (1961). Further support of the concept that myotonia must be associated with multiple abnormalities of membrane function comes from the work of Bryant (1962) on myotonic goats. He found the resting membrane potential normal but the conductance low, resulting in a prolonged utilization time of 1 second. He also showed that by replacing the extracellular chloride with sulphate a similar deficit, i.e., myotonia, could be induced in normal fibres. Of particular interest is the recent report by Winer, Martt, Somers, Wolcott, Dale, and Burns (1965) of the development of muscular spasms in patients treated with diazacholesterol, a cholesterol-lowering agent. The E.M.G. and clinical manifestations were those of myotonia. They were also able to produce myotonia in goats. The altered sterol synthesis and its effect on the muscle cell membrane will prove a further link in the understanding of this disorder. The subject of myotonia and the various aetiological considerations have been reviewed by Isaacs (1964b).

Myotonic-like bursts of activity may also be found in other conditions, such as polymyositis, where abnormal irritability of the muscle cell membrane is often present. Here, however, the bursts are not typical and are termed pseudomyotonia and are associated with other electrical manifestations of polymyositis.

\section{PRESENT STUDY}

It was while studying a large number of people with myotonia that a young boy, aged 12 , was encountered. His entire musculature was abnormally stiff. This stiffness was aggravated by movement and, resembling myotonia, showed a tendency to ease off as the muscles 'warmed up'. This improvement was short-lived, as the stiffness returned and waxed and waned though movement was continued. A further case in an adult was recognized within a short period of time. Both these cases were investigated and shown to have a disorder which was characterized by continuous muscle fibre activity. This activity persisted by night and by day, so that if the limbs were examined during sleep, stiffness was present. These cases were separated from the myotonias by the obvious clinical and electromyographic differences (Isaacs, 1961). They showed a gratifying response to sodium diphenylhydantoinate. Both patients lost their abnormal stiffness and returned to fairly normal living. After five years they are still well. Interruption of medication, however, is followed by return of the abnormality. Over this period it has been found that carbamyldibenzoazepin (Tegretol) may be used as a substitute for, or in combination with sodium diphenyl-hydantoinate, but the patients seem to prefer the latter.

The cases with continuous muscle-fibre activity were further separated from the 'stiff man' syndrome. Moersch and Woltman (1956) discussed the features of 14 cases of the 'stiff man' syndrome. This is characterized by severe, painful muscular spasms affecting particularly the proximal muscle groups. More recently Olafson, Mulder, and Howard (1964) reviewed the literature and carried out electromyography on three additional cases. All showed muscular activity which was considered to be composed of normal motor unit potentials as seen in voluntary contraction of normal muscles. Despite the persistent spasm of affected muscles, the reflexes were present or increased, further evidence suggesting a central cause for the abnormality. These cases have shown a good response to interneuronal inhibition effected by diazepam as used by Olafson et al. (1964). I have been able to confirm this gratifying response to diazepam in a local patient with the 'stiff man' syndrome who failed to respond to sodium diphenyl-hydantoinate. Conversely, the cases of continuous muscle-fibre activity are not affected by diazepam.

\section{CASE HISTORY}

Mr. A.R.M., an Indian male aged 20 (Fig. 3), was quite well until seven months ago, when he began to lose weight and complained of generalized body weakness. Within a short time he complained of a feeling of stiffness of the muscles affecting particularly the muscles of the hands. He noticed that the difficulty was most marked after a period of immobility and tended to improve with activity. But such improvement was not maintained and stiffness returned (despite continuous movement), waxing and waning in intensity, as previously described. Twitching movements in muscles and excessive sweating were also noted by the patient. 


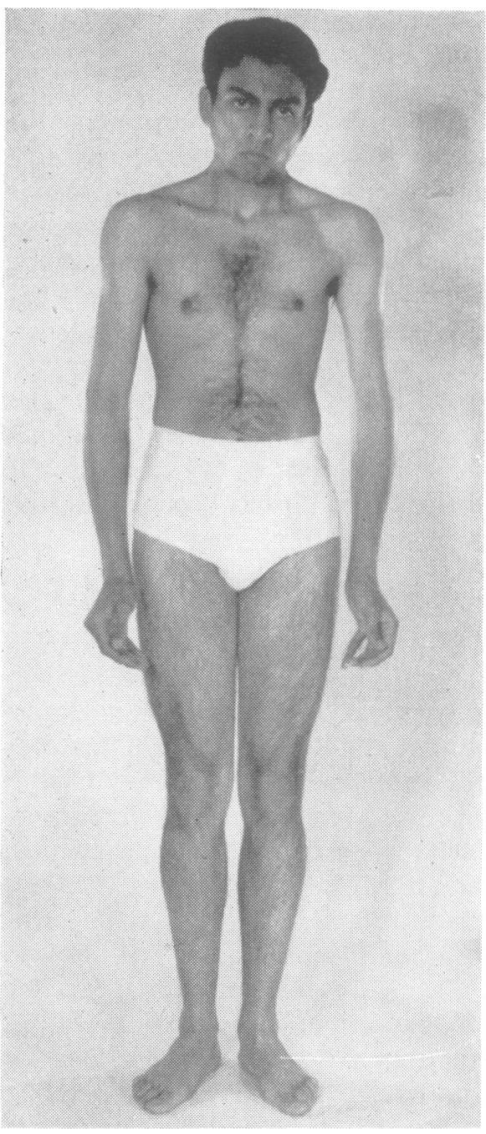

FIG. 3. The present patient.
Systematic questioning failed to reveal any specific cause which could be associated with the onset of the illness. The muscle trouble is not associated with any pain or abnormal sensation. He is one of a family of eight children, the other members being quite well. His mother and father are in good health.

Past illnesses were of a minor nature and he has not undergone any surgery. Intellectual development is considered normal.

His weight before the onset of the illness was $140 \mathrm{lb}$. This has now dropped to $123 \mathrm{lb}$. The muscle stiffness is deteriorating with the passage of time. There has been no difficulty as yet with breathing, mastication, or swallowing.

On examination his weight was $123 \mathrm{lb}$., height $66 \frac{1}{2}$ in., blood pressure $120 / 80 \mathrm{~mm} . \mathrm{Hg}$ (horizontal position, right arm) and the respiratory rate $17 / \mathrm{min}$. Physical examination was entirely within normal limits with the exception of the neuromuscular system. The muscles showed widespread fasciculation and muscular tone was considerably increased. This was most marked in the extremities, particularly the hands. There was no evidence of percussional myotonia in the muscles of the body or tongue. The tendon reflexes could not be elicited owing to the increased tone. All modalities of sensation were normal.

The electrocardiograph was normal. Interference from muscular activity was seen throughout the tracings.

Rectal examination was normal.

Urine was both microscopically and chemically normal.

A full blood count gave: $\mathrm{Hb} 15.4 \mathrm{~g} . \%$; leucocytes $8,400 \mathrm{~mm}$. (differential count normal); E.S.R. $3 \mathrm{~mm}$./one hour (Westergren); blood urea $22 \mathrm{mg} . \%$; serum sodium $143 \mathrm{mEq} . / \mathrm{l}$; potassium $4.5 \mathrm{mEq}$./one; calcium $10.4 \%$ $\mathrm{mg} . \%$; plasma $\mathrm{CO}_{2}$-combining power $23 \mathrm{mEq} . / \mathrm{l}$; chlorides $101 \mathrm{mEq} . / 1$; phosphorus $2.3 \mathrm{mEq} . / \mathrm{l}$; P.B.I.

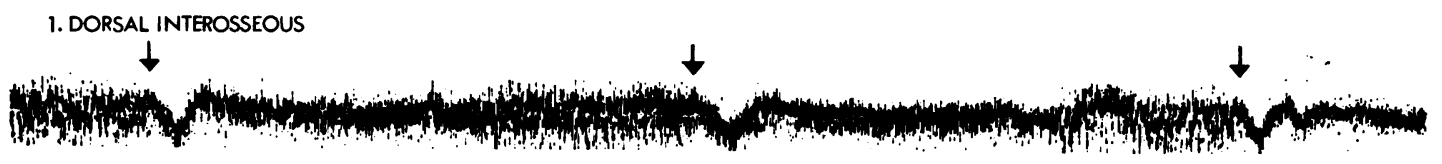

2. EXTENSOR COMMUNIS

I I MILLIVOLT

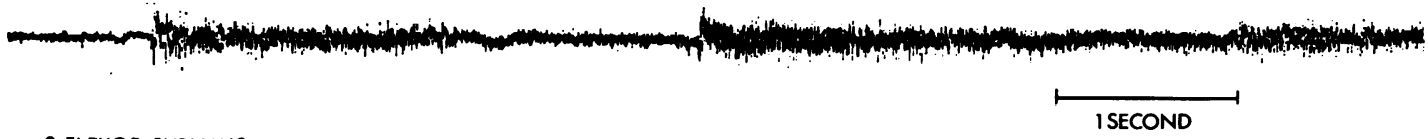

3. FLEXOR SUBLIMIS

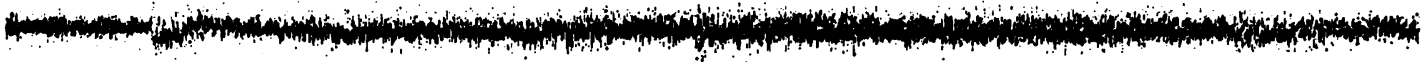

FIG. 4. Continuous motor-unit and muscle-fibre activity found at rest in the first dorsal interosseous, extensor communis and flexor sublimis muscles, respectively. 

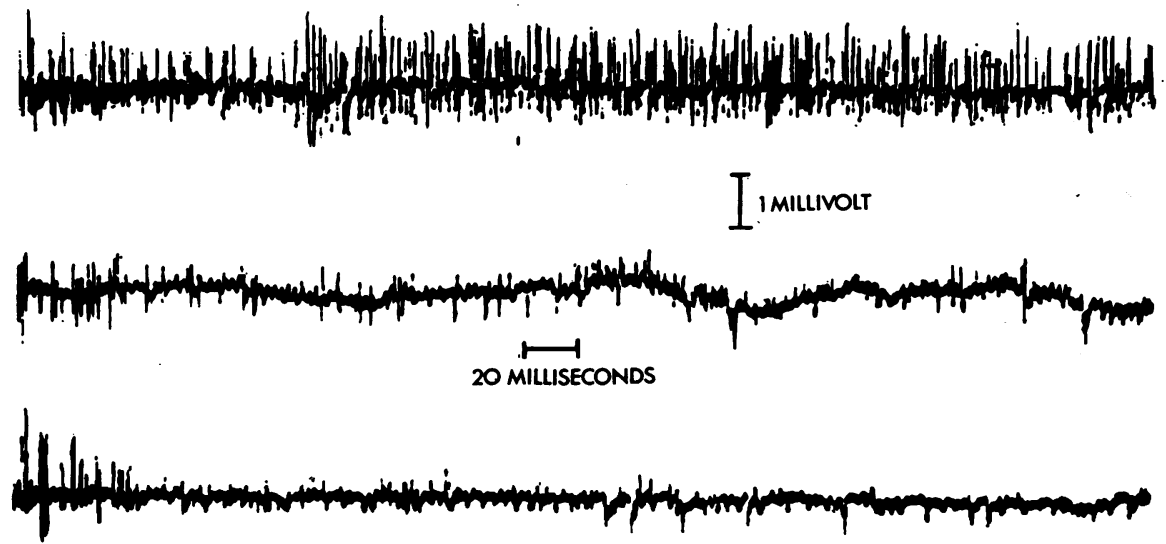

BRACHIAL BLOCK TOTAL ANAESTHESIA AND PARALYSIS

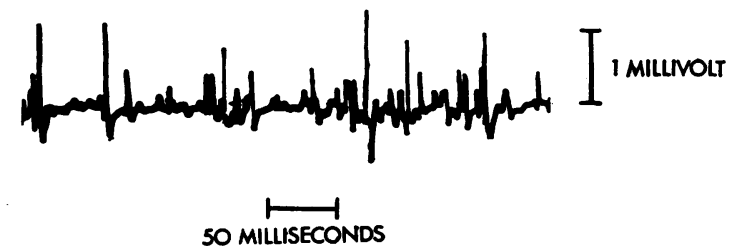

FIG. 5. Activity persists after complete brachial block.

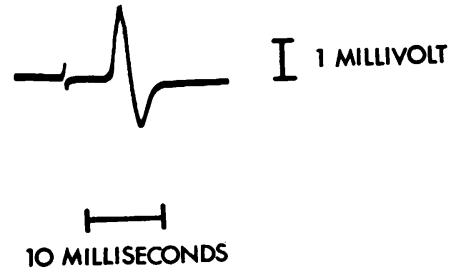

FIG. 6. Tracing of median nerve conduction following stimulation at the level of the wrist. The latency is slightly prolonged at $5 \cdot 2$ milliseconds.

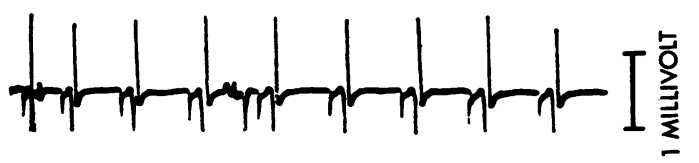

$$
\text { 5O MILLISECONDS }
$$

FIG. 7. The inhibitory effect on the spontaneous activity following faradic stimulation of the nerve.
$5 \cdot 2 \mu$ g. per $100 \mathrm{ml}$.; S.G.O.T. 23 units; serum creatine phosphokinase 80 sigma units/ml.; lactic dehydrogenase 90 international units; leucine aminopeptidase 100 units $/ \mathrm{ml}$. ; B.M.R. + 76; $\mathrm{O}_{2}$ consumption $360 \mathrm{ml}$./minute.

Several muscles, both proximal and peripheral, were examined by means of concentric needle electrodes. These showed the spontaneous discharge described in earlier cases. The muscle activity was continuous, the motor units varying in type and duration in a most bizarre fashion. Interspersed with apparently normal motor units were units of short duration and low voltage, obviously coming from individual muscle fibres. With strenuous contractions, the appearance was that of a full interference pattern with the additional activity of independent muscle fibres. Spontaneous activity was aggravated by voluntary activity and once again after strenuous continuous activity there occurred the curious silent period described in the earlier cases. Figure 4 demonstrates the bizarre spontaneous activity in the

\section{TÄBLE}

\begin{tabular}{|c|c|c|c|}
\hline & \multicolumn{3}{|l|}{ Nerve Conduction } \\
\hline & Right & Motor & Sensory \\
\hline $\begin{array}{l}\text { Median nerve } \\
\text { Ulnar nerve la }\end{array}$ & $\begin{array}{l}\text { Median nerve } \\
\text { Ulnar nerve } \\
\text { latency at wrist } \\
\text { atency at wrist }\end{array}$ & $\begin{array}{l}54 \mathrm{~m} . / \mathrm{sec} . \\
54 \mathrm{~m} . / \mathrm{sec} . \\
5.2 \mathrm{msec} \text {. } \\
3.4 \mathrm{msec} .\end{array}$ & $\begin{array}{l}60 \mathrm{~m} . / \mathrm{sec} . \\
58 \mathrm{~m} / \mathrm{sec} . \\
\text { (flexor pollicis brevis) } \\
\text { (abductor digiti } \\
\text { minimi) }\end{array}$ \\
\hline
\end{tabular}


first dorsal interosseous, extensor communis, and flexor sublimis muscles. The additional effect of voluntary activity is noted. Figure 5 demonstrates the effect of blocking the brachial plexus with procaine. Note that despite complete paralysis, the abnormal discharge persists though the aggravating effect of voluntary movement is eliminated. Peripheral block of the median and ulnar nerves was also performed and the blocking effect was assessed by proximal nerve stimulation. The spontaneous activity persisted.

Figure 6 illustrates the prolonged latency of median nerve conduction when stimulated at the wrist. Figure 7 illustrates an inhibitory effect on the spontaneous activity in muscle brought about by a tetanizing stimulus to the nerve. This patient's response to oral sodium diphenylhydantoinate gr. $1 \frac{1}{2}$ t.d.s. has been most satisfactory.

The importance of the syndrome of continuous muscle-fibre activity has been emphasized by Isaacs (1964a) with the postulate that the abnormal discharge represents an abnormality in the quantal release of acetylcholine by the motor nerve terminals.

In this patient the failure of proximal procaine nerve block to inhibit discharge in the relevant muscles, and the success of blocking and depolarizing agents in eliminating continuous activity have established that the anatomical site of ab- normality in continuous muscle fibre activity lies in the motor terminals. Figure 8 shows abolition of the spontaneous activity by succinylcholine after one and 12 minutes. Figure 9 shows the return of activity at 15 minutes. Figure 10 demonstrates the complete lack of response to pentothal anaesthesia (note the aggravating effect of passive stretching). The muscle response to percussion and direct electrical stimulation during succinylcholine depolarization is entirely normal. These cases show a marked sensitivity to the blocking action of curare, as described by Isaacs (1961).

An analogy was drawn between the spontaneous discharge of the motor nerve terminals and epileptic central discharges which suggested the use of phenobarbitone. This, however, was tried in high dosage without success. Sodium diphenyl-hydantoinate, on the other hand, in doses of gr. $1 \frac{1}{2}$ three to four times a day, produced a return to an almost normal state within three days. Figure 11 illustrates the electrical activity persisting at rest in the flexor pollicis brevis muscle two days after treatment was started. Note the motor units interspersed with short-duration activity low-voltage potentials of separate muscle fibres.

DORSAL INTEROSSEOUS

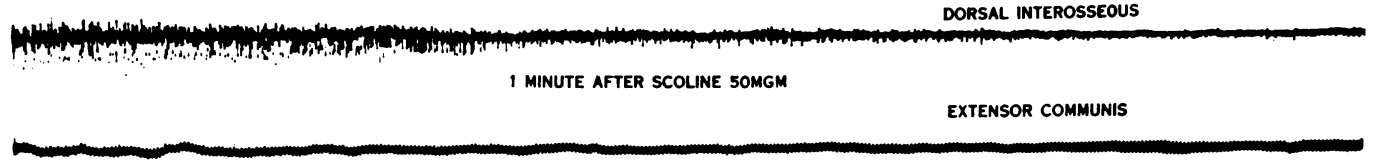

FLEXOR SUBLIM!S

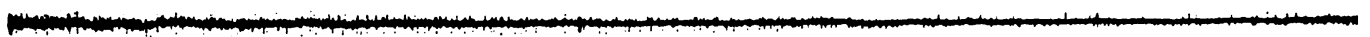

12 MINUTES

ISECOND

FIG. 8.
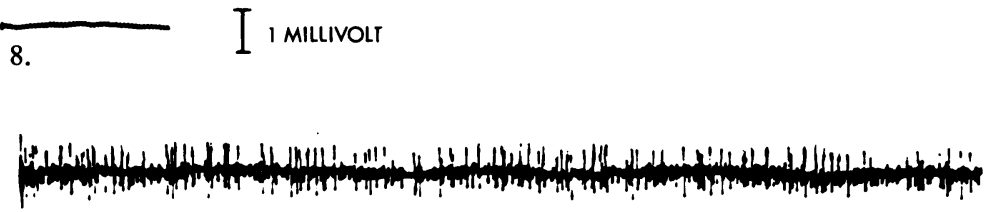

15 MINUTES AFTER SCOLINE 5OMGM

FIG. 8. Abolition of the spontaneous activity following intravenous administration of succinylcholine. The tracings were taken after one and 12 minutes.

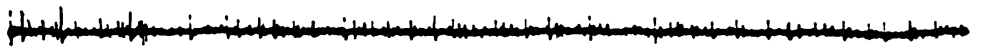

I I MILLIVOLT

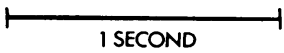

FIG. 9. Return of spontaneous activity 15 minutes after the administration of intravenous succinylcholine.

FIG. 9 


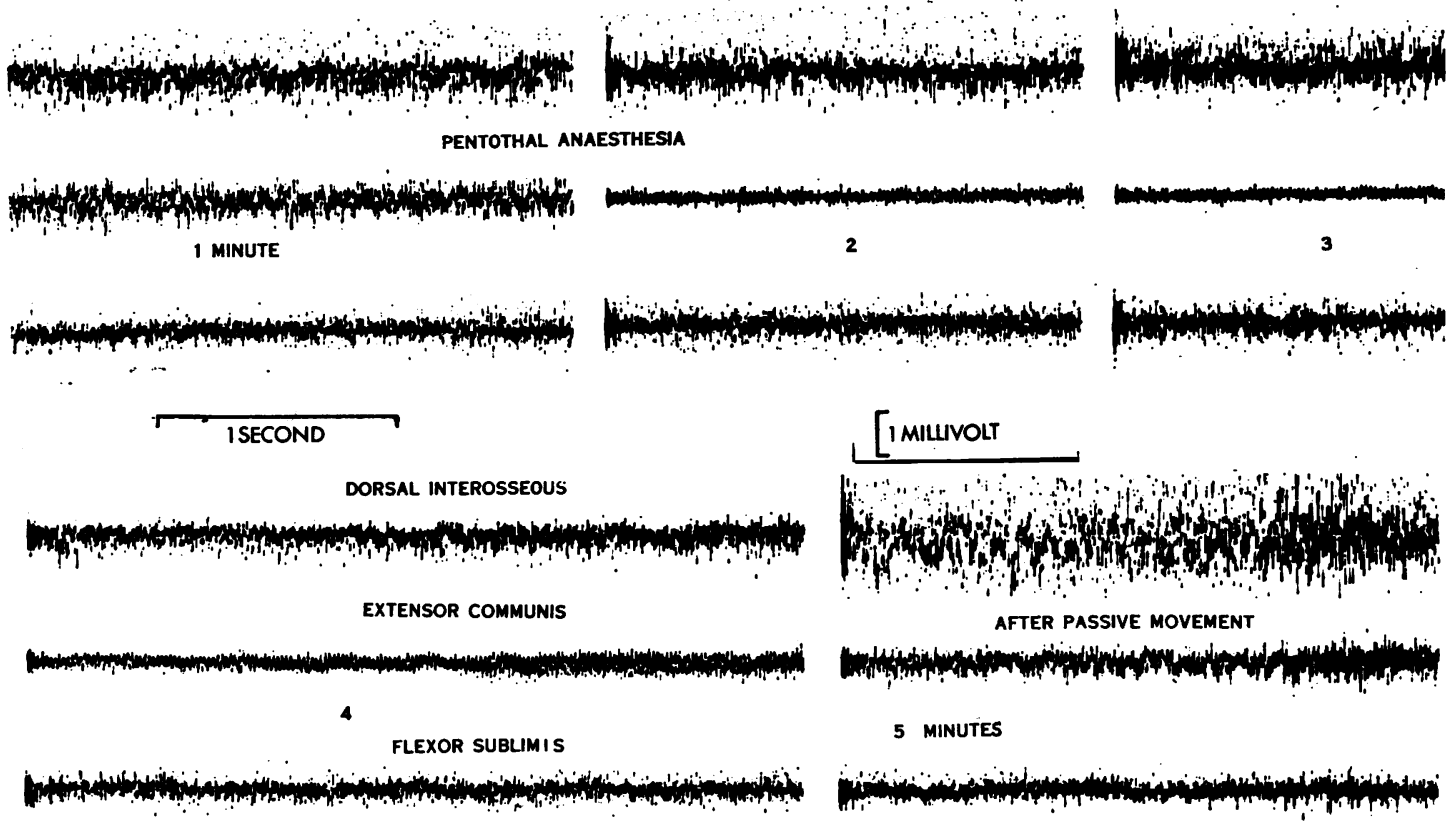

FIG. 10. The lack of response to pentothal anaesthesia and the aggravating effect of passive stretching of the muscle.

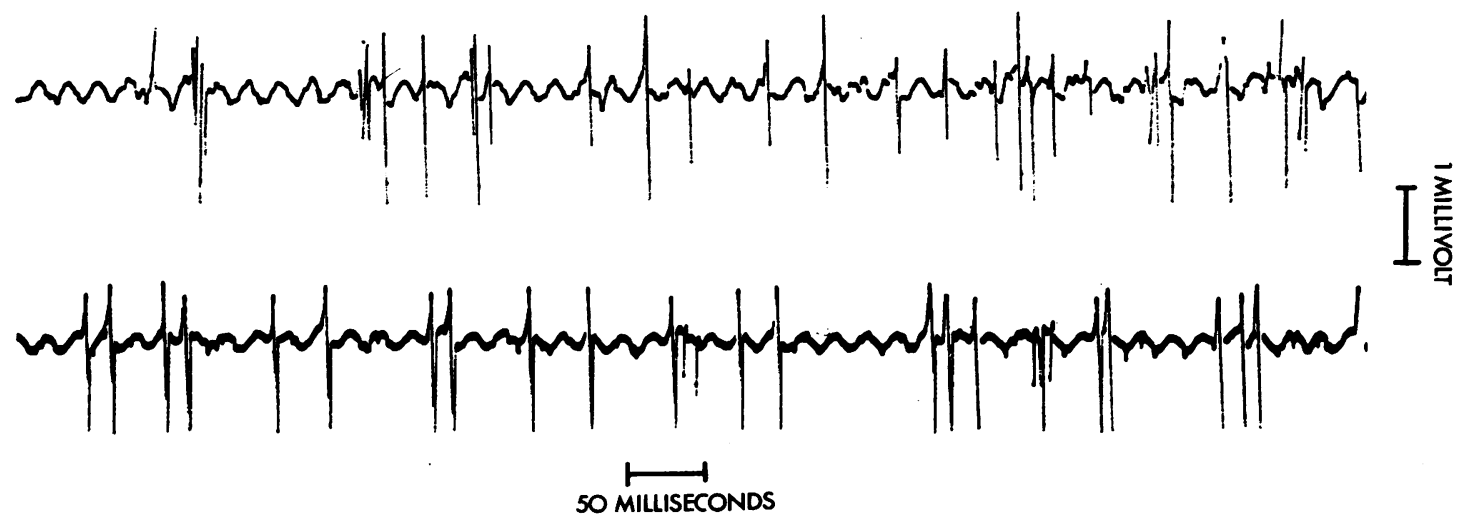

FIG. 11. Marked improvement in spontaneous activity two days after commencement of therapy. The electrical activity is both motor-unit and from individual muscle fibres. The trace is superimposed on a 50 cycle/second artifact.

\section{DISCUSSION}

In considering the action of sodium diphenylhydantoinate on excitable tissues, Woodbury, Koch, and Vernadakis (1958) were able to show that the main anticonvulsive effect correlates with the increased sodium pumping action of nerve and muscle cells.

It has long been appreciated that botulinus toxin blocks the terminal branches of the motor nerve (Brooks, 1954, 1956), indicating that a specific excitability is inherent in this particular region of the motor nerve.

Standaert (1963) found that the application of a tetanizing stimulus of the order of 400 stimuli per second for a period of 10 seconds to peripheral nerves in cats caused a disturbed response in the motor nerve terminals. These experiments have shown conclusively that an abnormal state of spontaneous activity may be induced in the motor nerve terminals in otherwise normal nerves.

Parisi and Raines (1963) demonstrated in chloral- 
ose anaesthetized cats that diphenyl-hydantoinate administered in anticonvulsant doses abolishes the post-tetanic repetitive activity described above. The effect was found maximal 90 minutes after intravenous injection of the anticonvulsant. The effect of the diphenyl-hydantoin was specific in that it abolished the post-tetanic repetitive activity without blocking transmission as judged by the appearance of the twitch response. The importance of the diphenyl derivative has been established by Raines (1964), who found sodium hydantoin without effect in cats.

Mertens and Zschocke (1965) were able to confirm my findings in this syndrome in their study of three additional cases. Methyline blue vital staining of the terminal nerve fibres and motor end-plates in one of their cases was normal, while cholinesterase staining revealed a somewhat shrunken appearance of the subneural structures.

Mertens and Zschocke chose to describe the cases under the heading of 'neuromyotonia', on the basis that 'continuous muscle-fibre activity' gave no indication of the abnormality in the terminal motor fibres which was shown in the original paper. Myoneural dysfunction, neural myotonia, myoneural epilepsy, neurotonia, peripheral neuromuscular rigidity, were originally rejected as being unsatisfactory for one or other reason. To emphasize the abnormal acetylcholine release, a paper was written under the heading of 'quantal squander' in 1964. The term 'neuromyotonia' was rejected on the basis that pains have been taken to separate this syndrome from the myotonias, as there is no connexion with myotonia and too often confused with it. The term myotonia must be reserved to describe that specific muscular disorder with its characteristic electromyographic findings.

In the three cases it was noted that the latency of median nerve conduction at the wrist was delayed. This improved in time with treatment. The exact cause is obscure but probably relates to median nerve compression brought about by the continuous and abnormal tension in the flexor muscles which result in wrist flexion.

If one accepts the hypothesis that there exists in these cases of continuous muscle fibre activity an abnormal release of acetylcholine at the motor fibre terminals, one must explain as well the abnormal sensitivity to curare. The response to the depolarizing action of succinylcholine administered intravenously in a dose calculated on the basis of the subject's weight, appeared normal. This gives a crude indication, though indirect, that the depolarization threshold is normal.

In order to explain the sensitivity to curare it may be necessary to postulate that in these cases there exists an associated defect in the postsynaptic membrane. There is ample evidence in myasthenia gravis to suggest that the postsynaptic membrane acts abnormally to depolarizing drugs in that a dual depolarizing blocking action is commonly encountered. The abnormal sensitivity to blocking agents is well known. In myasthenia gravis it has been shown as well that a defect lies in the motor fibre terminal with inadequate release of acetylcholine (Dahlbäck, Elmquist, Johns, Radner, and Thesleff, 1961). It is probable then that, as in myasthenia gravis, the defect in continuous muscle fibre activity will be found both in the acetylcholine release mechanism and in the post-synaptic membrane.

\section{SUMMARY}

The sixth case with continuous muscle-fibre activity to be reported is described. The separation of this syndrome from myotonia and the 'stiff man' syndrome is briefly discussed.

The defect in these cases lies in the terminal motor fibres where an abnormal acetylcholine quanta release occurs and the possibility of an associated abnormality of the postsynaptic membrane is considered. This condition is in some $\frac{}{\infty}$ respects opposite to that found in myasthenia gravis and represents a second disorder of myoneural function.

I wish to thank Dr. S. Katz for referring this third case for investigation, and the photographic unit of the Department of Medicine of the Witwatersrand University Medical School for the photographs.

\section{REFERENCES}

Brooks, V. B. (1954). The action of botulinum toxin on motor-nerve filaments. J. Physiol., 123, 501-515.

(1956). An intracellular study of the action of repetitive nerve volleys and of botulinum toxin on miniature end-plate potentides. J. Physiol. (Lond.), 134, 264-277.

Bryant, S. H. (1962). Muscle membrane of normal and myotonic goats in normal and low external chloride. Fed. Proc., 21, 312. No. 2 (abstr.).

Buchthal, F., Engbaek, L., and Gamstorp, I. (1958). Paresis and hyperexcitability in adynamia episodica hereditaria. Neurology (Minneap.), 8, 347-352.

Creutzfeldt, O. D., Abbott, B. C., Fowler, W. M., and Pearson, C. M. (1963). Muscle membrane potentials in episodic adynamia. Electroenceph. clin. Neurophysiol., 15, 508-519.

Dahlbäck, O., Elmquist, D., Johns, T. R., Radner, S., and Thesleff, S. (1961). An electrophysiologic study of the neuromuscular junction in myasthesia gravis. J. Physiol. (Lond.), 156, 336-343.

Isaacs, H. (1961). A syndrome of continuous muscle-fibre activity. J. Neurol. Neurosurg. Psychiat., 24, 319-325.

(1964a). Quantal squander. S. Afr. J. Lab. clin. Med., 10, 93-95.

- (1964b). Thesis on myotonia. Witwatersrand University.

Mertens, H. G., and Zschocke, S. (1965). Neuromyotonie. Klin. Wschr., 43, 917-925.

Moersch, F. P., and Woltman, H. W. (1956). Progressive fluctuating muscular rigidity and spasm ('stiff-man' syndrome). Report of a case and some observations on 13 other cases. Proc. Mayo Clin., 31, 421-427. 
Olafson, R. A., Mulder, D. W., and Howard, F. M. (1964). 'Stiffman' syndrome: A review of the literature, report of three additional cases and discussion of pathophysiology and therapy. Ibid., 39, 131-144.

Parisi, A. F., and Raines, A. (1963). Diphenylhydantoin suppression of repetitive activity generated in nerve endings. Fed. Proc., 22, 390 . No. 1372 (abstr.).

Raines, A. (1964). Personal communication.

Standaert, F. G. (1963). Cited by Parisi and Raines (1963). Mechanism of post-tetanic potentiation (P.T.P.) in cat slow and fast muscles. Fed. Proc., 22, 309. No. 891 (abstr.).
Van der Meulen, J. P., Gilbert, G. J., and Kane, C. A. (1961). Familia hyperkalemic paralysis with myotonia. New Engl. J. Med. 264, 1-6.

Winer, N., Martt, J. M., Somers, J. E., Wolcott, L., Dale, H. E., and Burns, T. W. (1965). Induced myotonia in man and goat. $J$. Lab. clin. Med., 66, 758-769.

Woodbury, D. M., Koch, A., and Vernadakis, A. (1958). Relation between excitability and metabolism in brain as elucidated by anticonvulsant drugs. Neurology, 8, (Minneap.), suppl. 1, pp. 113-116. 